\title{
Continuing Professional Development of One-Person Librarians in Ireland: A Qualitative Study
}

\author{
Eva Hornung \\ University of Sheffield, UK
}

\begin{abstract}
Continuing professional development $(C P D)$ is crucial to most professions today. Library and Information professionals are no exception. They need to be up-to-date in order to serve their patrons effectively and efficiently. One cohort of librarians, however, is arguably under even more pressure to update their knowledge: one-person librarians $(O P L s)$. These are qualified information providers, who either work on their own in their respective organisations or with clerical support. Yet they are expected to provide their patrons with the latest information in extra fast time. There are many barriers to CPD for OPLs. The following article is based on some findings derived from a PhD research project. By exploring the qualitatively different ways in which solo librarians in Ireland understand the notion of CPD, this phenomenographic study aimed at providing an insight into people's perceptions of that term. It examined their experiences of the various ways and circumstances in which they learn. Based on an analysis of 30 semi-structured interviews five qualitatively distinct categories emerged ranging from up keeping for organisational goals only to a holistic lifelong learning view. These conceptions in turn informed librarians' opinions on which types of CPD were seen as being successful and effective.
\end{abstract}

\section{Introduction}

This research study investigated how one-person librarians (OPLs) in the Republic of Ireland perceived of the concept of "continuing professional development" (CPD) and which kind of development activities they found to be effective. OPLs are professionally qualified library and information professionals, who either work as the sole information provider in their organisation or with clerical non-professional staff as support. The focus was on OPLs or "solo librarians" as this was a cohort of librarians on which little research had been done previously. This is despite the fact that experts in the field of OPL librarianship estimated that one in three librarians in the world was an OPL [1].

Through her own experience and anecdotal evidence, the researcher was aware that OPLs faced many obstacles when it came to pursuing CPD. Many could not attend formal training taking place outside their own organisations since they could not get anybody to cover for them in the library. Also, financial support was often hard to come by in times of limited resources as experienced by many Irish institutions in the last ten years. Additionally, many development opportunities do not address the specific needs of OPLs who are "all-rounders", which means that they have to be able to do a vast amount of tasks.

Yet CPD is central to the role of librarians who are supposed to be up-to-date with relevant knowledge not only in their own field of Library and Information Science (LIS), but also of the subject area they are working in. OPLs in particular are expected to be able to respond quickly and efficiently to the demands of a modern workplace.

This article expands on the poster presented by the researcher. She will firstly look at the underlying study. The second part will be on the practical outcomes of the study, on what has happened since the project had concluded.

\section{Literature review}

The researcher conducted a thorough literature review in several fields: LIS, education (especially adult education, professional development, workplace and lifelong learning), staff and organisational management as well as organisational psychology. Of interest to this article are some research studies which examined CPD in relation to information professionals. A few of these are mentioned here.

Several themes emerged and were investigated further. CPD in libraries was an expanding field of interest in LIS. Farmer and Campbell, who studied information professionals' perceptions of CPD in relation to the concept of 'success' exposed an underlying lack of understanding of what CPD was and gathered different opinions on the characteristics of CPD. Their interviewees felt that CPD could take many forms and different strategies were important for different people at different stages of their careers and in different geographical locations [2].

The size of the library was identified as the most prominent factor in librarians' self-directed, work-related learning in a study by Varlejs. A lack of support in terms of reimbursement and time off did 
not deter the participants in her study, as selfdirected learning was predominantly taking place in the workplace. She also found that they were motivated and likely to be professionally active librarians, but not necessarily high achievers [3].

The factors influencing the participation of Ontario's public library reference librarians in professional development activities were at the centre of Chan's and Auster's research. They found 'managerial support' to have a positive influence on taking part in formal activities and 'motivation' and 'managerial support' for involvement in informal activities. Overall, the authors found high levels of professional commitment, which, according to them, has never been studied before as a contributing factor in relation to partaking in training [4].

The researcher was struck by how little research had been conducted on CPD for OPLs. Some studies looked at OPLs as part of the librarians they investigated, but only a few provided in-depth research.

Shuter's study was one of the first of its kind specifically on OPLs, or One Man Bands (OMBs) as they had been known as, their working conditions and job satisfaction. She found that the most disappointing aspect of their jobs was the amount or (more accurately) lack of training they received. She also saw short courses, along with the development of librarian networks, as a way forward for these OMBs. [5]

Internal training provision and external short courses were compared in Slater's 1988 study. In relation to $\mathrm{OMBs}$, she discovered that out of her sample, $71 \%$ did not receive any internal training and $19 \%$ only minimal informal training, which $90 \%$ described as being an unsatisfactory situation. $23 \%$ of these one-person units felt that training was quite impractical for them, a statement only $2 \%$ in other small units in larger library and information services made. This also translated into the external short course sector, where OMBs were more likely than staff in larger units not to attend (21\% and 2\%, respectively). $50 \%$ of the OMBs surveyed cited "lack of funds" as the reason for not attending. Also, courses should not last longer than one day according to $35 \%$ and not longer than 2 days for $23 \%$ of the OMB sample. The most likely post-course outcome for OMBs was "specific acquisition of new skill” (mentioned by 73\%). [6]

OMBs and their training needs were at the heart of Williamson's thesis [7]. She observed an overall lack of co-operation between LIS schools, professional associations and commercial training organisations. This was a barrier to improving the training situation for solo librarians. Most OMBs felt that Library School education did not prepare them for working on their own, which was especially true for special libraries settings. Williamson, however, also recommended more assertiveness from the OMBs fighting their case with their employers. The main deterrents to attendance of training courses were time, cost, lack of encouragement, problems with location and poor organisation. The preferred course format was short "courses at a local training centre" of a half to one day's duration, followed by "series of talks given by a professional association" (p. 94). In-house, distance and selftaught activities were not popular among this group, which the researcher attributed to the lack of contact with other librarians [7].

\section{The study}

The present researcher realised that her study would have to address some fundamental assumptions. The literature review showed her that no two researchers could agree on what CPD actually was or what it meant to individual professionals.

Over time two main research questions developed:

- What are the Irish OPLs' conceptions of successful and effective CPD?

- How do OPLs in Ireland experience different methods of CPD?

These questions warranted a qualitative research approach (see below in part 4). Having sent out a call for participation to several professional email lists, the researcher received a lot of expressions of interest. She proceeded to interview 30 LIS professionals, which were based around the country. The aim was to have maximum variation in terms of demographic details and work experience of participants (see Table 1).

Table 1. Summary of variables

\begin{tabular}{|l|l|}
\hline Gender: & 5 men, 25 women (ratio 1:5) \\
\hline Experience: & $\begin{array}{l}\text { 8 had 0-2 years of experience, 22 had 2 and } \\
\text { more (ratio 4:11) }\end{array}$ \\
\hline Location: & 11 rural, 19 urban \\
\hline Settings: & $\begin{array}{l}\text { Health: 9, Special: 9, Academic: 6, } \\
\text { Corporate: 3, School/Public: } 3\end{array}$ \\
\hline
\end{tabular}

Librarianship is traditionally a female profession and the ratio mirrors the gender divide in Irish libraries. Anecdotal evidence suggested that it took OPLs about two years to feel settled in their new role as solo librarians, which is why the level of experience was divided between "0-2 years" and "2 and more years". There was also a huge range of general professional library experience with some participants only starting off and some nearing the end of their career. Most librarians worked in urban 
settings, but the researcher also managed to talk to OPLs outside more populated areas. The breakdown of type of library shows the wide variety of OPL workplaces. Other factors, which the researcher recorded, were level of support by management (both time and money), and whether or not OPLs had clerical help.

Interviews lasted between 35 minutes and over an hour, and followed an interview schedule. This semistructured schedule had been approved of by the ethics committee of the university and had been tested in a pilot study. Main data collection took place between September 2008 and June 2009. The researcher also kept reflective journals, which formed part of the data collection.

All interviews were transcribed verbatim by the researcher and analysed in several stages using the transcripts.

\section{Phenomenography}

Having investigated several other qualitative methods the researcher settled on Phenomenography, which had been used in educational studies since its inception in the 1970s at the University of Gothenburg in Sweden. It is not a methodology in itself, but has been described as "...rather a way of an approach to - identifying, formulating, and tackling certain sorts of research questions, a specialization that is particularly aimed at questions of relevance to learning and understanding in an educational setting" [8]. Phenomenography looks at the variation in understanding a phenomenon as participants in this group have experienced it. These conceptions can be grouped into so-called "categories of description", which in turn are qualitatively different from each other. The outcome of a phenomenographic study is the "outcome space", which consists of said categories of description and also of "dimensions of variations", which are reoccurring themes that are evident in all categories, albeit experienced in a different way.

It is important to keep in mind that every OPL could hold conceptions at one stage of the interview that fitted into one category, but others that fell into a different one depending on the experiences they were focusing on at a certain stage. Phenomenography is not concerned with individual responses as such, but rather with the totality of conceptions across that particular group at that particular point in time. The idea is that there is only a limited amount of different ways of perceiving of a phenomenon and that a researcher would be able to describe the relationship the participants had with this specific object.

\section{Findings}

Data analysis was rigorous and underwent many cycles of categorising and re-examination. Five categories of description (see Table 2) and four dimensions of variations (see Table 3 ) emerged.

\section{Table 2. Categories of description}

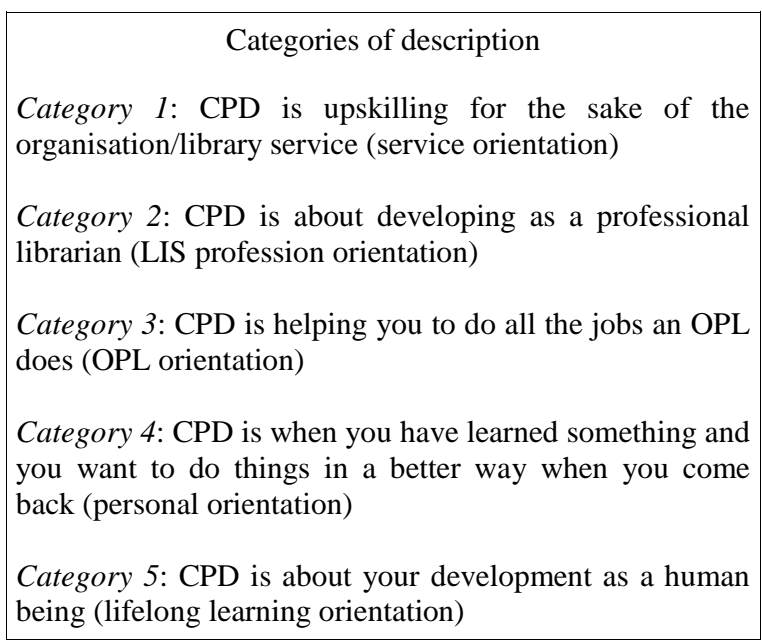

Categories 1 and 3 had a focus on work-related CPD, whereas categories 2 and 4 displayed a more personcentred emphasis. Category 5 was the most holistic of all categories by looking at a person's lifelong learning journey encompassing both personal and work environments.

\section{Table 3. Dimensions of variation}

Dimensions of variation
Dimension 'role' - responsibility, motivation and support
Dimension 'time' - current job or career or life in general
Dimension 'style' - formal or informal with examples
Dimension 'networking' - type of networking, reasons for
doing it

Of interest to this article is the dimension 'style', which shows the different types of CPD activity OPLs were involved in. The following will show how that dimension changed in each category.

\subsection{CPD activities reported - Category 1}

In category 1 both formal and informal CPD activities were of interest with formal particularly strong. These included training courses (both within the organisation and outside of it), seminars, academic degrees, even being involved in work committees.

Informal here was mainly using the Internet (email lists, online tutorials, and other free resources) and on-the-job learning. 
All of these were conducted with a view to enhancing the goal of the organisation, as this excerpt from the interviews shows:

"It's generally kind of learning skills to do with your current role and your future career. The only think I've realised in the last while, over chatting about it, is that so much of my, of any kind of CPD I've currently done is really, is very much tied to my current role and it's difficult to kind of see beyond that." (Interviewee 2)

\subsection{CPD activities reported - Category 2}

In category 2 , the focus is on what it means to be a LIS professional.

"I suppose continuing with, you know, I can't think of any synonyms, it's 'ongoing', it's 'post your main qualification' and it should continue over a long period, I suppose, is built into that. The professional bit is that it relates to your, well, I suppose, two parts: one, your profession as a librarian and two, what you happen to be doing as a librarian, which may or may not be the same thing, because not every librarian is working in fields that were traditionally envisaged when they qualified. So I guess the idea it's the idea of both deepening experience and broadening it from the original professional training." (Interviewee 23)

Here, formal and informal means of CPD were also used, but informal was often more important. The wish for accreditation of CPD activities or a more formal structure of recording and reporting to the professional body was very strong.

In terms of formal activities, the following were mentioned: Courses, conferences, seminars; training courses as part of a conference and case studies. Informal included hands-on, people showing you things; email lists, help forums, web seminars, online learning, correspondence courses, email, phone; reading, especially professional literature; informal networking evenings.

\subsection{CPD activities reported - Category 3}

In category 3 , the emphasis was much more on informal activities. Again, the Internet featured dominantly: Web, email, email lists, online tutorials and training provided by database providers. "Taking up the phone and ringing a colleague in another library" was another informal way of keeping up as was "reading journal articles" and general "on-thejob activities".

Here respondents felt their OPL status and the pressures that entailed more keenly than in other categories. "We have to decide what's important. Yes, I mean, we will respond to demands, but we also have to keep ourselves aware of what's going on and then we have to know what we need to know." (Interviewee 7)

\subsection{CPD activities reported - Category 4}

Category 4 was slightly different in that the CPD activity happened and the OPL only realised later that a need had been there. "If they're useful, if I come back having learned something and particularly if I comeback feeling energised and excited and want to do things, which just happened. Particularly I find the conferences, I usually come back with something relevant that I want to do." (Interviewee 7)

Sometimes one event triggered an interest in another type of CPD. "...So, yeah, so, basically they'd be searching skills, new ways of doing things, that kind of thing. Ehm... you know that's, that's what I mean. And again, it's kind of ad hoc, you know, something comes along. I couldn't say to you now that I need to update my skills in $\mathrm{x}$, $\mathrm{y}$ or $\mathrm{z}$ area, I couldn't say that to you. But something might come along and I might say 'oh, yeah, I don't know a lot about that' or 'I need to do something about that'. Ehm, again, I might be doing something at work and I might realise "well, I need to do something about that', you know." (Interviewee 19)

Both formal and informal were strong in this category. Formal CPD included short seminars as well training and refresher courses. Informal activities were listed as Internet (email lists, newsgroups, restricted groups); hands-on activities, people showing you how to do things (shadowing people); newsletters from vendors and reading journals.

\subsection{CPD activities reported - Category 5}

Category 5 was strong on all opportunities and had a lifelong and life-wide learning focus. "Mmmmh.... for myself, personally, yeah? Oh, your mind would go numb if you didn't continue to learn, like. Everyone should learn for life, I suppose. Lifelong learning! Ehm, that's, yeah, just keep your brain active as well as obviously keeping on top of your job, to do your job to the best of your ability." (Interviewee 10)

Every experience was seen as a CPD activity: "Oh, I mean just those were the two areas that I would see continuing professional development for me is in doing one or two day courses that are organised by other libraries or library associations or do a Diploma or Certificate or a Master's or PhD in something else, that's gonna improve for you. But then, you'd pick up, I suppose continuing professional development can be picking up from each action of the people you meet as well, just from a day to day, and just realising what people are doing and going away and having a Google search and, ehm, seeing what's there, d'you know, and seeing if you can get information from the Internet on it or obviously from a recognised source! But I suppose it 
opens up, there are so many sources for it if you're not closed, if your mind isn't closed to what's out there, you'll see opportunities everywhere." (Interviewee 30)

\section{Practical outcomes of the study}

As can be gleaned from the findings above, different categories need different types of CPD. "One size fits all" training programmes, for example, do not work for solo librarians. Some of the help OPLs could get is provided for by the professional body for library and information professionals in Ireland, the Library Association of Ireland (LAI). It has responded to this study. The work-related categories (categories 1 and 3) are perhaps more difficult to cater for as the CPD needs are often specific to a certain work environment. But the more personal categories 2 and 4 as well as the lifelong category 5 are being addressed in some of the policies and events run by the LAI.

A new understanding of what CPD means to individuals has led to a renewed debate. The establishment of a CPD policy for librarians in Ireland [9] was the first step in that direction. General restructuring of the LAI saw the introduction of a CPD committee, which has responsibility for promoting and accrediting of CPD events to all its members. Critically, it will also support further research into this area, which will help create a body of knowledge [10].

A new emphasis of informal learning opportunities can be discerned in the profession. CPD includes learning outside the workplace, which is why several libraries have started programmes on job swaps and job shadowing, which OPLs also participate in, sometimes even on a Saturday.

Networking with other information professional was seen as in important means of keeping up-todate across all categories (evidently a 'dimension of variation'). The LAI has a strong history in providing links between professionals, but a new emphasis has been placed on informal, virtual connections. OPLs based on the Western seaboard, which is less urban than the Dublin area in the East, have benefitted from Webinars and other online facilities organised by the Western Regional Section of the LAI. More librarians seem to engage in email lists and LinkedIn groups than ever before. By sending a request to the list, one can potentially reach hundreds of other information professionals. Tapping into their knowledge and resourcefulness usually yields results for the enquirer and the services they provide. Twitter has also become a more important tool for continuing professional development despite reservations by many Irish librarians [11].

More CPD opportunities for OPLs were created. The Academic \& Special Libraries Section (A\&SL) and the Career Development Group (CDG) of the
LAI initiated "LibCamp" or "Library Camp", a socalled "unconference". The idea, which had been developed in library circles in the UK, has become very popular in Ireland. Not unlike "real" conferences, members are invited to pitch their mini talks and workshops, which they will then present to their colleagues. Three of these are happening at the same time and participants are encouraged to walk around and take part. What is different is that everybody is potentially an expert and can advance the pitch further. The emphasis is on collaboration, rather than lecturing. In its third year, LibCamp [12] brings librarians from across Ireland to Dublin to debate trends and learn about new projects. Many of the participants come from smaller information centres. During one Saturday in early summer OPLs can share and meet other librarians over home-made cake.

The A\&SL started organising "informal networking evenings", which allow OPLs and nonOPLS alike to meet with other librarians. It includes a tour of a new library or a new facility, to be followed by a visit to a local pub. OPLs, who cannot make it to the official event because of work commitments, can join the group later for an informal exchange at the pub. This gives them the opportunity to bounce ideas off, to learn about a new resource or simply to hear what is happening in other larger libraries. Many new forms of collaboration between OPLs have also started thanks to this initiative.

Of course all of these initiatives are of little use unless OPLs make use of them. It will be up to them to continue their professional development. Feedback from her OPL colleagues give the researcher high hopes for the future, however, as this is a very active, engaged and enthusiastic group of information professionals.

\section{Conclusions}

The study started a debate about the importance of CPD for OPLs. When the researcher presented her findings at conferences in Ireland and beyond, she received a lot of interest from other researchers and practitioners. Contacts have been made with OPLs in other countries and it is hoped that follow up research might come out of these new connections.

In Ireland it has helped to enhance the profile of OPLs. Many solo librarians have approached the researcher with a view to establish a subgroup for OPLs within the LAI structure.

The author hopes that the model that these categories of description describe will aid OPLs and other librarians in their understanding of their own CPD needs. She also proposes that it could be adapted to suit small enterprises, which are facing some of the same restrictions OPLs encounter when it comes to CPD. 


\section{Acknowledgements}

The author would like to thank all study participants and her supervisor, Ms Sheila Webber.

\section{References}

[1] J. Siess, “One-Person Library”, In: Drake, M. A. (Ed.), Encyclopedia of Library and Information Science: Vol. 3; Lib-Pub, Second Edition, Marcel Dekker, New York, 2003, pp. 2209-2217.

[2] J. Farmer, J. and F. Campbell, Continuing Professional Development and Career Success: is there a causal relationship? (British Library Research and Innovation Report 112), British Library Research and Innovation Centre, London, 1988.

[3] J. Varlejs, "On their own: Librarians' self-directed, work-related learning”, Library Quarterly, 69 (2), April, 1999, pp. 173-201.

[4] D. C. Chan and E. Auster, "Factors contributing to the professional development of reference librarians", Library and Information Science Research, 25 (3), 2003, pp. 265286.

[5] J. Shuter, The Information Worker in Isolation: Problems and Achievements, Bradford: MCB University Press, Bradford, 1984

[6] M. Slater, Internal Training and External Short Courses: a study of informal continuing education in the special sector of the library/information field (British Library Research Paper 52), British Library Board, Boston Spa, 1988.

[7] J. B. Williamson, The further education and training needs of one-man-band library and information workers, unpublished M.Lib. thesis, Aberysthwyth, University of Aberystwyth, 1990.

[8] F. Marton and S. Booth, Learning and Awareness, (The Educational Psychology series), Lawrence Erlbaum Associates, Mahwah, NJ, 1997.

[9] Library Association of Ireland (2006), 'Policy Paper on Continuing Professional Development', Library Association of Ireland; https://libraryassociation.ie/libraryassociation-ireland/committees-panels-task-forces/ education-committee-cpd/policy-paper (18 May 2015)

[10] Library Association of Ireland Education Committee: Continuing Professional Development (2014), 'Terms of Reference', Library Association of Ireland; https://libraryassociation.ie/sites/default/files/LAI\%20CPD \%20ToR\%20Agreed\%20131114.pdf (18 May 2015)

[11] M. Dalton, ““What would I tweet?': Exploring New Professionals' Attitudes Towards Twitter as a Tool for Professional Development", Journal of Library Innovation, 4 (2), 2013, pp.101-110.
[12] Career Development Group of the Library Association of Ireland, 'Library Camp 2015'; https://laicdg.wordpress.com/library-camp-2015/ (19 May 2015) 